\title{
Cost savings related to decreased preterm birth in a program of centering pregnancy for Hispanic women
}

\begin{abstract}
Objective: To calculate the cost savings of a program of group prenatal care (Centering Pregnancy) due to the reduction in preterm births and low birth weight among infants of mothers who participated in the program. To compare the costs of the program with the costs of traditional care in terms of preterm birth and low birth rates.
\end{abstract}

Methods: The outcomes of infants born to mothers receiving care either as traditional prenatal care or group (Centering Pregnancy) was compared. Data was obtained from chart abstraction and information previously published. Published costs of care for preterm infants and low birth weight infants were used to compare cost among models of care (traditional vs. group).

Results: The cost for intensive neonatal care (NICU) is significantly lower for infants born of women receiving Group care (Centering Pregnancy) because there were less infants requiring this service. We calculated savings of approximately $\$ 1.4$ million due to the reduction in preterm births. In addition, savings of approximately $\$ 1.8$ to $\$ 3.5$ million were calculated due to a reduction of births less than 32 weeks. Additional savings of approximately $\$ 3.7$ million were related to the reduction of infants born with weights less than $1,500 \mathrm{gm}$.

Conclusion: A program of Group Prenatal care (Centering Pregnancy) demonstrated a reduction in the rate of preterm births and low birth weight infants thus reducing the costs of NICU care and extended hospitalization.
Volume 5 Issue I - 2017

\section{Carmen D Zorrilla,' Ana Mosquera, ${ }^{3}$ Silvia Rabionet D, ${ }^{2}$ Juana I Rivera-Viñas,' Dianca I Sierra Vega, ${ }^{3}$ Lourdes De Jesus, ${ }^{3}$ Isalis Sánchez-Peña, ${ }^{3}$ Keimari Méndez,' Susana Schwarz,' José Hawayek' \\ 'Department of Obstetrics and Gynecology, UPR School of Medicine, USA \\ 2UPR School of Public Health, Nova Southeastern University, USA \\ ${ }^{3}$ Maternal Infant Studies Center (CEMI), Department of Obstetrics and Gynecology, UPR School of Medicine, USA}

Correspondence: Carmen D Zorrilla, MD, Professor, Department of Obstetrics and Gynecology, UPR School of Medicine, Maternal-Infant Studies Center (CEMI), PO Box 365067 San Juan, PR, USA, Tel 00936-5067/787-753-59I3/77।4740, 766-0025, Fax 787-77I-4739,

Email carmen.zorrilla@upr.edu

Received: March 29, 2017 | Published: April 19, 2017

Keywords: cost-savings, group prenatal care, centering pregnancy, infant outcomes, preterm birth

\section{Abbreviations: PTB, preterm birth; LBW, Low Birth Weight; $\mathrm{CHI}$, centering healthcare institute, NICU, neonatal intensive care units}

\section{Introduction}

Preterm birth (PTB) is one of the most important causes of perinatal mortality and morbidly in the developed world. ${ }^{1}$ The birth of a preterm infant results in significant health consequences to the infant and emotional and economic costs for families and communities. ${ }^{2}$ PTB is defined as a birth before 37 weeks of gestational age. In 2015, preterm birth affected about 1 of every 10 infants born in the United States. ${ }^{3}$ The National Center for Health Statistics has reported that about 500,000 premature live births occur annually in the United States alone. ${ }^{4}$ In addition to the health problems associated with preterm birth, there is a broad of emotional and financial costs and lost opportunities for families. ${ }^{3}$ In a 2006 report, the Institute of Medicine described the high rate of premature births in the United States as "a public health concern that costs society at least \$26billion a year, ${ }^{5}$ or $\$ 51,600$ per infant born preterm. ${ }^{3}$ The March of Dimes has described these costs as follows: $\$ 16.9$ billion in medical and health care costs for the baby, $\$ 1.9$ billion in labor and delivery costs for mom, \$611million for early intervention services, \$1.1billion for special education services, and \$5.7billion in lost work and pay for people born prematurely. ${ }^{6}$ The initial hospitalization costs of a preterm infant are nearly always double the cost of a term infant. ${ }^{7}$ Costs per infant hospitalization were highest for extremely preterm infants, although the larger number of moderately preterm/low birth weight infants contributed more to the overall costs. Preterm/low birth weight infants in the United States account for half of infant hospitalization costs and one quarter of pediatric costs, suggesting that major infant and pediatric cost savings could be realized by preventing preterm birth. ${ }^{8}$ Moreover, a paper published by Petrou discussed that there is an inverse relationship between gestational age or birth weight and hospital service costs during the neonatal period. ${ }^{9}$ The Premature Birth report card, published by the March of Dimes, showed a reduction in the rates of PTB for the USA from $12.8 \%$ in 2006 to $11.7 \%$ in 2011 and to $9.6 \%$ in $2015 . .^{10}$ On the other hand, in the 2015 report card for Puerto Rico, one of every 8 infants $(11.8 \%)$ was born preterm. ${ }^{11}$ Despite decreasing trends of $19.9 \%$ in $2006,17.6 \%$ in 2011 and $11.8 \%$ in 2013, the island continues to be above the national rate and targets for PTB about 1.3 times that of the rate for the USA. ${ }^{12}$

The impact of preterm birth and its associated co-morbidities (including long-term disabilities) can be devastating to a family requiring additional resources to cover Neonatal Intensive Care Unit (NICU) care, multiple specialty visits, and other associated costs. Any program or intervention that reduces the risks of incidence of PTB will have positive impact on families reducing the burden of care and reducing overall costs. We have previously reported the reduction of 
preterm birth and low birth weight in a program of group prenatal care (Centering Pregnancy). ${ }^{13}$ This model of care has been demonstrated in Randomized Control Trials (RCT) of having a reduction in preterm births and having increases in birth weights among participants of group care. ${ }^{14-18}$ The Institute of Medicine recommends a multidisciplinary research agenda aimed at improving the prediction and prevention of preterm labor and better understanding the health and developmental problems to which preterm infants are more vulnerable. ${ }^{19}$ Cost-benefit modeling have been used by other investigators to demonstrate that Centering Pregnancy can be financially sustainable and possibly an income generator for outpatient clinics. ${ }^{20}$ Moreover, a study performed in South Carolina, which used a different methodology to ours, showed savings of $\$ 2.3$ million due to the implementation of group prenatal care due to a reduction of premature births and subsequent birth outcomes such as LBW and NICU visits. ${ }^{21}$ With the aim of determining additional benefits of a program that has reduced preterm births, with the eventual reduction in health disparities, and improvement in the chances of survival and quality of life of the affected infants, we decided to calculate the costs of some of the most expensive elements associated to preterm births (NICU) and compare such costs per the differences in preterm birth rates in traditional care vs Centering Pregnancy. This article presents a preliminary cost analysis comparing traditional (individual) vs. group prenatal care (Centering Pregnancy) based on the results (already published) of a study that evidenced that infants born from mothers who received group care had better outcomes. ${ }^{13}$ The cost information obtained from a study regarding Hospital Stay for Newborn published by the Agency for Healthcare Research Quality will be used for the analysis. ${ }^{22}$

\section{Materials and methods}

On February 8, 2012, the Centers for Medicare \& Medicaid Services announced a funding opportunity to test the effectiveness of specific enhanced prenatal care approaches to reduce the frequency of premature births among pregnant Medicaid or Children's Health Insurance Program (CHIP) beneficiaries at high risk for preterm births. ${ }^{23}$ This program was titled Strong Start for Mothers and Infants. Our program was funded through this initiative and we were able to implement a group prenatal care model (Centering Pregnancy) at the University Hospital in San Juan, Puerto Rico. Our project titled: "Transformación Prenatal" started as a pilot program in 2013 and eventually was defined as the universal model of care for the high risk prenatal care clinic at our hospital. This program was successful in implementing Centering Pregnancy for the first time in Puerto Rico in a complex environment: tertiary care hospital with a high-risk clinic and a training program. The program was accredited (certified) by the Centering Healthcare Institute (CHI) in January 2017. Data from the patients' outcomes was obtained from chart review and compared with patients who delivered in the same hospital but did not participated from the group prenatal care model. All women had access to interventions such as $17-\mathrm{OH}$ progesterone for those with a history of prior preterm birth. When compared with women who received traditional prenatal care (individual visits) with varying educational contents, the outcomes of the infants of women enrolled in group care demonstrated higher gestational age at birth, increased birth weights and Apgar scores and a lower proportion of preterm birth at any of the different categories. Group care showed lower rates of preterm birth $(27.7 \%$ vs. $34.1 \%)$ and births earlier than 32 weeks (3.6\% vs. $11.9 \%)$ (Table 1$).^{13}$

\section{Group prenatal care model of care}

Centering Pregnancy is an innovative model of group prenatal care that integrates physical assessment with extensive health education and group support. ${ }^{24}$ It incorporates three major components: assessment, education, and support. Participants meet with their care provider ingroup ( 8 to 12 participants) for longer periods (usually 90-120minutes) than traditional visits. The groups are composed of participants with similar gestational ages and characteristics to facilitate discussion, develop a support network, and increase a sense of empowerment. Participants attend 10 sessions throughout pregnancy. ${ }^{25}$

\section{Traditional prenatal care}

Traditional care generally consists of individual patient and provider visits at regular intervals throughout pregnancy. Historically, regular prenatal care visits offer a unique opportunity for providers to interact with the family unit, providing guidance and care to mothers, infants and often other family members. ${ }^{26}$ The U.S. Public Health Service has defined and outlined the content for prenatal care in a publication titled Caring for our Future: The Content of Prenatal Care, which remains a gold standard for care. They suggest that prenatal care clinicians provide:

\section{i. Risk assessment,}

ii. Medical and psychosocial intervention, and

iii. Health promotion. ${ }^{27}$

\section{NICU cost estimates}

In order to make estimate the impact of our program on cost savings by reducing the rate of preterm birth, we searched for published cost information. A study published by the Agency for Healthcare Research Quality titled "Hospital Stay for Newborn, 2011" was used as reference for NICU and other related costs. On average, term newborns stayed in the hospital for 3.4days and incurred average hospital costs of $\$ 3,200$. Newborns that were preterm or had low birth weight or respiratory distress syndrome had higher average lengths of stay and higher average costs compared to all newborns. Preterm newborns had hospital stays averaging 14.3days with mean costs of $\$ 21,500$. Among newborns with low birth weight, those who weighed less than 1,500grams had hospital stays averaging 42.6days with mean costs of $\$ 76,700$ compared to 10.9 days and $\$ 14,000$ for those weighing 1,500 grams or more. ${ }^{22}$ Infants with a moderately low birth weight can cost $46 \%$ more than infants born at normal birth weight. The U.S. Agency for Healthcare Research and Quality reports that medical costs for the average very low birth weight infant are $\$ 79,000$, compared to $\$ 1,000$ for a normal newborn. ${ }^{22}$ Using these published costs, we estimated the cost of premature births by gestational age and weight category in the patients from our program. This comparison was specifically for births of infants whose mothers had traditional prenatal care or group prenatal care. In order to be able to compare both groups, we calculated the numbers in a base of 1,000 births for each category (because we had 1,112 infants in traditional care and 614 infants in group care). Using the proportions of preterm births for each group (centering Pregnancy or Traditional Prenatal care) we estimated the absolute number of 1,000 births to compare the costs and calculate savings (Table 2). 
Table I Outcomes group prenatal care vs. traditional care

\begin{tabular}{lll}
\hline Births & Traditional care & Group prenatal care \\
\hline $\mathrm{N}=1,726$ & $\mathrm{n}=1,112$ & $\mathrm{n}=614$ \\
$<37$ wks (n) & 379 & 170 \\
$<37$ wks (\%) & $34.10 \%$ & $27.70 \%$ \\
$<32$ wks (n) & 132 & 22 \\
$<32$ wks (\%) & $11.90 \%$ & $3.60 \%$ \\
$<1,500 \mathrm{gm}(\mathrm{n})$ & 78 & 17 \\
$<1,500 \mathrm{gm}(\%)$ & $7.60 \%$ & $2.80 \%$
\end{tabular}

Table 2 Estimate number of births by category based on 1,000 births per original proportion (Traditional vs. Group Care)

\begin{tabular}{lll}
\hline Births & Traditional care & Group prenatal care \\
\hline$<37$ wks. (\%) & $34.10 \%$ & $27.70 \%$ \\
Estimate by 1,000 births <37wks (n) & 341 & 277 \\
$<32$ wks (\%) & $11.90 \%$ & $3.60 \%$ \\
Estimate by 1,000 births <32wks (n) & 119 & 36 \\
$<1,500$ gm (\%) & $7.60 \%$ & $2.80 \%$ \\
Estimate by 1,000 births $<1,500 \mathrm{gm}(\mathrm{n})$ & 76 & 28 \\
\hline
\end{tabular}

\section{Results and discussion}

This study discusses the cost savings of Centering Pregnancy (Group Prenatal Care) by reducing the costs associated to the care of preterm birth (PTB) infants in comparison to traditional care models. The cost for intensive neonatal care (NICU) is significantly lower for infants born of women receiving Group care (Centering Pregnancy) because there were fewer infants requiring this service.
We calculated savings of approximately $\$ 1.4$ million due to the overall reduction in preterm births. In addition, savings of approximately $\$ 1.8$ to $\$ 3.5$ million were calculated due to a reduction of births less than 32weeks. Additional savings of approximately $\$ 3.7$ million were related to the reduction of infants born with weights less than $1,500 \mathrm{gm}$. We do not include here the impact on the population served in terms of patient satisfaction, or reduction in family stress and/or quality of life associated with the care of preterm infants (Table 3) (Figure 1).

Table 3 Costs and saving analysis of traditional care vs. group care

\begin{tabular}{|c|c|c|c|}
\hline Births & Traditional care & Group prenatal care & Difference (Cost-Saving) \\
\hline $\begin{array}{l}\text { Estimate by } 1,000 \text { births } \\
<37 \text { wks. (n) }\end{array}$ & 341 & 277 & \\
\hline $\begin{array}{l}\text { Published cost per infant: } \\
\$ 21,500\end{array}$ & $\$ 7,331,500(\$ 7.33 \mathrm{M})$ & $\$ 5,955,500(\$ 5.96 \mathrm{M})$ & $\$ 1,376,000(\$ 1.38 \mathrm{M})$ \\
\hline $\begin{array}{l}\text { Estimate by } 1,000 \text { births } \\
<32 \mathrm{wks} \text { (n) }\end{array}$ & 119 & 36 & \\
\hline $\begin{array}{l}\text { Published cost per infant: } \\
\$ 21,500-\$ 41,610\end{array}$ & $\begin{array}{l}\$ 2,558,500(\$ 2.56 \mathrm{M})- \\
\$ 4,951,590(\$ 4.95 \mathrm{M})\end{array}$ & $\begin{array}{l}\$ 744,000(\$ 0.74 \mathrm{M}) \\
-\$ 1,497,960(\$ 1.50 \mathrm{M})\end{array}$ & $\begin{array}{l}\$ 1,814,500(\$ 1.81 \mathrm{M})- \\
\$ 3,453,630(\$ 3.45 \mathrm{M})\end{array}$ \\
\hline $\begin{array}{l}\text { Estimate by } 1,000 \text { births } \\
<1,500 \mathrm{gm}(\mathrm{n})\end{array}$ & 76 & 28 & \\
\hline $\begin{array}{l}\text { Published cost per infant: } \\
\$ 76,300\end{array}$ & $\$ 5,798,800(\$ 5.80 \mathrm{M})$ & $\$ 2,136,400(\$ 2.14 \mathrm{M})$ & $\$ 3,662,400(\$ 3.66 \mathrm{M})$ \\
\hline
\end{tabular}




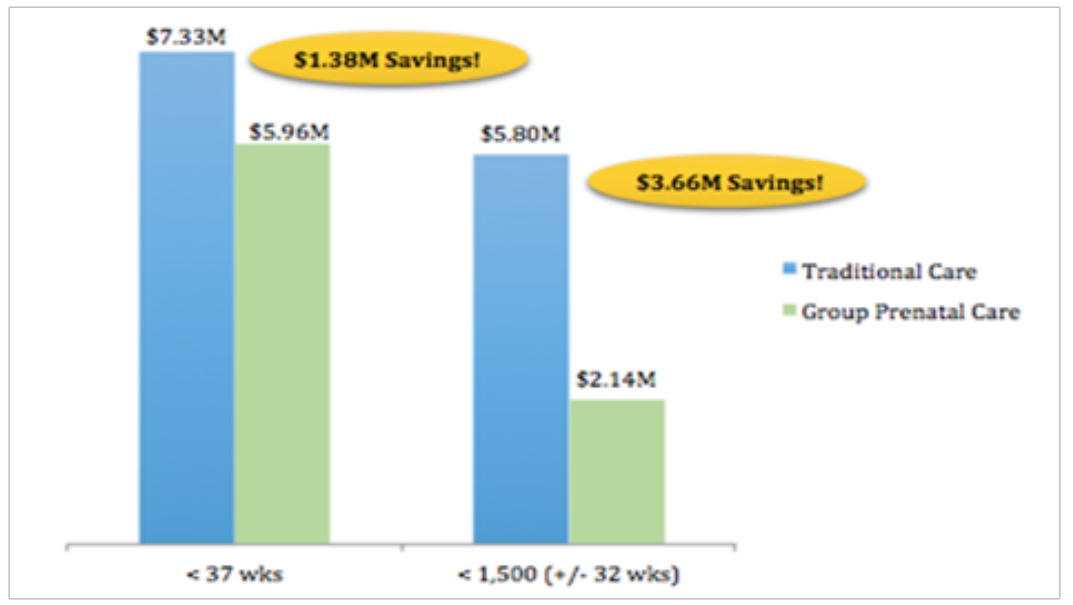

Figure I Costs and saving: traditional care vs. group care.

\section{Conclusion}

The economic burden of preterm birth is substantial and can be decreased if programs such as the one presented are implemented in order to reduce preterm birth and low birth weight. A program of Group Prenatal care (Centering Pregnancy) has demonstrated reductions in preterm births and improvements in birth weights compared to the traditional model of care. We calculated the costsavings of such program by comparing known costs associated to the care of preterm infants. The Program demonstrated costs savings of \$1.38Million on infants born $<37$ weeks GA, $\$ 1.8$ to $\$ 3.5$ million on infants born $<32$ weeks and $\$ 3.7$ Millions on infants weighting $<1,500 \mathrm{gm}$. The cost for Group Prenatal care for approximately 1,000 pregnant women is estimated in the amount of \$234,123 (\$234 per women), which includes training and facility implementation cost of $\$ 41,872$ (incurred only once), full time personnel (Facilitators/ Nurse, Coordinator and Administrative staff), and education materials provided to each pregnant women (e.g. brochures, Centering Book Guide, among others). After start-up costs are incurred, the cost of group prenatal care per pregnant women is reduced to $\$ 220$. The investment of implementing this group prenatal care model impacts positively in delivery outcomes, reducing costs of care per infant born. Considering the cost savings in the reduction of preterm infant care costs, the program still represents a good investment with an impact of approximately $\$ 1,141,877$ million of savings, better outcomes and a brighter future for the infants of mothers in the program.

One limitation of this analysis is the fact that we used reported costs from the USA for the years 2011. Therefore we are not calculating the cost differences using the actual or local costs. In spite of this limitation, the actual local costs might be similar to those published. In addition, we are comparing costs for the same services (NICU) except for different proportions of need due to the differences in preterm birth rates $(34.1 \%$ vs $27.7 \%)$. Another limitation is the retrospective type of analysis of the data on preterm births. Nevertheless, all patients were delivered at the same hospital, with a relatively similar ethnicity (Hispanic). Our analysis further confirms that reducing the rate of preterm deliveries in Puerto Rico with an innovative prenatal care model (Centering Pregnancy) will translate not only in substantial savings in the medical expenses of infants born preterm or with low birth weight, but might eventually translate into better survival and quality of life for these infants and their families. Moreover, different studies have shown that the benefits of Centering Pregnancy could be even higher in the long run because of preterm infants have a higher probability of becoming children with chronic disease and developmental problems.

\section{Acknowledgements}

The authors want to acknowledge the contribution of the University Hospital administrative and directive officials including: Mrs. Ada Reyes (General Nursing Supervisor), Mrs. Betsy Ruiz (Assistant Clinical Affairs), Dr. Ricardo Moscoso (Hospital Medical Director), and Mr. Jorge Matta (Hospital administrator), whose leadership and support made possible the implementation of the program. In addition, the High Risk Prenatal Clinic Director Dr. Alberto de la Vega and the staff and faculty were instrumental in the implementation and overall operation of the program. This protocol was approved by the MSC Institutional Review Board (1350115). The Group Prenatal care program was funded by the Centers for Medicare \& Medicaid Services, (CMS) Innovation Center grant number 1D1CMS331141.

\section{Conflict of interest}

The author declares no conflict of interest.

\section{References}

1. Chang H, Larson J, Blencowe H, et al. Preventing preterm births: analysis of trends and potential reductions with interventions in 39 countries with very high human development index. Lancet. 2013;381(9862):223-234.

2. Societal Costs of Preterm Birth. In: Behrman R, et al. editors. Preterm Birth: Causes, Consequences, and Prevention. USA: The National Academies Press,; 2007. p. 398-429. 
3. Preterm Birth. Centers for Disease Control and Prevention; 2015.

4. Sneiderman P. Students Design Early Labor Detector to Help Prevent Premature Births. USA: John Hopkins University; 2010.

5. Preterm Births Cost U.S. \$26 Billion a Year. The National Academies of Sciences, Engineering, and Medicine; 2006.

6. The impact of premature births on society. USA: March of Dimes; 2015.

7. Petrou S, Sach T, Davidson L. The long-term costs of preterm birth and low birth weight: Results of a systematic review. Child Care Hlth Dev. 2001;27(2):97-115.

8. Russell RB, Green NS, Steiner CA, et al. Cost of hospitalization for preterm and low birth weight infants in the United States. Pediatrics. 2007;120(1):e1-e9.

9. Petrou S. Economic consequences of preterm birth and low birthweight BJOG. 2003;110(20): 17-23.

10. 2016 Premature Birth report card. USA: March of Dimes; 2015. p. 1-3.

11. 2015 Premature Birth report card. USA: March of Dimes; 2015. p. 1-4.

12. Resumen General de la Salud en Puerto Rico. USA: Departamento de Salud; 2014. 218 p.

13. Zorrilla C, Sánchez I, Mosquera A, et al. Improved infant outcomes with group prenatal care in Puerto Rico. J Obstet Gynaecol. 2017;1(1):e1-9.

14. Grady MA, Bloom KC. Pregnancy outcomes of adolescents enrolled in a centering pregnancy program. J Midwifery Wom Heal. 2004;49(5):412420 .

15. Ickovics JR, Earnshaw V, Lewis J, et al. Cluster randomized controlled trial of group prenatal care: Perinatal outcomes among adolescents in New York City health centers. Am J Public Health. 2016;106(2):359-365.

16. Ickovics JR, Reed E, Magriples U, et al. Effects of group prenatal care on psychosocial risk in pregnancy: Results from a randomized controlled trial. Psychol Health. 2011;26(2): 235-250.
17. Ickovics JR, Kershaw TS, Westdahl C, et al. Group prenatal care and perinatal outcomes. Obstet Gynecol. 2007;110(2):330-339.

18. Ickovics JR, Kershaw TS, Westdahl C, et al. Group prenatal care and preterm birth weight: Results from a matched cohort study at public clinics. Obstet Gynecol. 2004;102(5):1051-1057.

19. Newnham J, Dickinson J, Hart R, et al. Strategies to prevent preterm birth. Front Immunol. 2014;5: 584.

20. Rowley R, Phillips L, O'Dell L, et al. Group prenatal care: A financial perspective. Matern Child Hlth J. 2016;20(1): 1-10.

21. Gareau S, López A, Loudermilk B, et al. Group prenatal care results in medicaid savings with better outcomes: a propensity score analysis of centering pregnancy participation in south carolina. Matern Child Hlth J. 2016;20(7): 1384-1393.

22. Kowlessar N, Jiang J, Steiner C. Hospital Stays for Newborns, 2011. HCUP Statistical Brief \#163. USA: Agency for Healthcare Research and Quality; 2013. p. 1-12.

23. Centers for Medicare and Medicaid Services. Strong Start for Mothers and Newborns Initiative. USA: Center for Medicare \& Medicaid Service; 2016.

24. Novick G, Reid A, Lewis J, et al. Group prenatal care: model fidelity and outcomes. Am J Obstet Gynecol. 2013;209(112):e1-6.

25. Centering Model Information. USA: Centering Healthcare Institute; 2016.

26. Lathrop B. A systematic review comparing group prenatal care to traditional prenatal care. Nurs Women Health. 2013;17(2):118-130.

27. Caring for our future; the content of prenatal care. National Institutes of Health (DHHS), USA: Government Printing Office; 1989. p. 1-138. 